\title{
Uterine Fibroids In A Tertiary Health Centre South East Nigeria
}

\author{
Obuna JA, Umeora OUJ, Ejikeme BN, Egwuatu VE
}

\section{Department of Obstetrics \& Gynaecology, Ebonyi State University Teaching Hospital Abakaliki, Ebonyi State, Nigeria}

\begin{abstract}
Background: Uterine fibroids are common benign tumours of the female reproductive tract.

This study evaluated the clinical presentations and the treatment of fibroids at Ebonyi State University Teaching Hospital over the 5-year period (2001-2005).

Methods: A retrospective analysis of all cases of uterine fibroids admitted into the gynaecological ward of the Ebonyi State University Teaching Hospital (EBSUTH) over the five-year period (2001 2005).
\end{abstract}

Results: Uterine fibroids accounted for $13.6 \%$ of all gynaecological admissions during the period. It was found predominantly during the third and fourth decades of life in nulliparas and women of the higher socio economic class. Primary infertility (22.9\%), lower abdominal mass (21. $6 \%)$, menstrual abnormalities(15.9\%), lower abdominal pain $(15.9 \%)$ and anaemia (11.8\%) were the common clinical presentations while abdominal myomectomy was the commonest modality of treatment employed (90\%).

Conclusion: Uterine fibroid is common among gynaecological admissions in lgbo women of Southeastern Nigeria. Infertility is a common presentation necessitating abdominal myomectomy in majority of the cases.

Key words: Fibroids, Igbo, Infertility, Myomectomy, wound breakdown, menorrhagia.

Date accepted for publication $28^{\text {th }}$ July 2008

Nig J Med 2008; 447-451

Copyright $\odot 2008$ Nigerian Journal of Medicine

\section{Introduction}

Uterine fibroid is the commonest tumour encountered in females of reproductive age group and the single most common indication for hysterectomy prior to menopause $^{1,2,3}$. The prevalence rate varies from $2050 \%$ of women depending on the age, ethnicity, parity, and assessment modality ${ }^{4}$. A prevalence rate of $77 \%$ has been reported on postmortem uterine specimen $\mathrm{s}^{1,4}$. It accounts for $6.6 \%$ of all gynaecological admissions at lle-lfe ${ }^{2}$ and $10 \%$ at Korle Bu teaching hospital $\left.\right|^{5}$.

Only $25 \%$ of patients with fibroids exhibit symptoms ${ }^{24,6}$. Abnormal uterine bleeding is the commonest symptom and ranges from menorrhagia to pre-menstrual bleeding and metrorrhagia'. Other symptoms include lower abdominal swelling, pressure symptoms affecting the urinary and gastrointestinal systems and infertility. Some of the complications of uterine fibroid include: torsion of the pedunculated fibroids, infection, ascites, infertility, anaemia from abnormal uterine bleeding, degenerative changes and polycythemia. Sarcomatous changes occur in $0.2-0.5 \%$ of cases ${ }^{24,6,7}$.

Treatment option depends on the symptoms, signs and location of the tumour, the patient's age, parity, future reproductive wish and general health ${ }^{7,8}$. Management may be conservative, medical or surgical. Conservative management is undertaken when the mass is less than 12 weeks gestational size, cervical myoma less than $3 \mathrm{~cm}$ in diameter and when no symptoms are found in a woman who is more than 45 years or has attained menopause, as the fibroid mass tends to shrink with the loss of estrogen stimulation ${ }^{8}$.

Medical treatment is indicated in patients who are approaching menopause or in postmenopausal women since fibroid regresses after menopause ${ }^{8}$. It is also indicated to shrink the fibroid mass or reduce vascularity especially when blood transfusion is to be avoided or when Pfannenstiel instead of midline incision or vaginal rather than abdominal route of surgery is preferred ${ }^{\top}$. Medical treatment can also be used in patients who are not fit for surgery or who refused to consent to surgery or in a difficult surgical patient such as obese patients ${ }^{7}$. Medical options involve hormonal treatment with $\mathrm{GnRH}$ analogues: Goserelin, Buserelin, Leuprolide ${ }^{7,9}$. GnRH analogues may be given as monthly injections, nasal spray or implant ${ }^{7,9}$. In severe cases where other treatment modalities for menorrhagia have failed, anti-fibrinolytic agents such as trenaxemic acid (Ponstan ${ }^{\circledR}$ ) may be used as may be, anti-estrogens and Danazol?

The greater proportion of Ebonyi State is made of the low socio-economic group with tendency towards high parity, which appears not to favour the occurrence of uterine fibroids ${ }^{8}$. No documentation exists in literature on the topic of uterine fibroid among gynaecological 
admissions in EBSUTH, a tertiary health institution that serves as the major referral center for the population. This study evaluates the epidemiology, clinical presentation and management modalities of uterine fibroid at the Ebonyi State University Teaching Hospital, Abakaliki.

\section{Methodology}

\section{Study Background}

Ebonyi State University Teaching Hospital (EBSUTH) is one of the two tertiary health facilities in Ebonyi State located at Abakaliki, the state capital. It receives referrals from all parts of the state and the neighbouring states of Benue, Enugu, Cross-River and Abia. Specialist Gynaecologists with Resident Doctors run the gynaecological clinics everyday of the week (Monday to Friday). Diagnosis of uterine leiomyoma is made mainly on clinical grounds and supported by pelvic ultrasonography.

Subsequent management is individualized with consideration of symptomatology, age, parity, size of fibroid and reproductive wish of the patient.

\section{Study Population}

All cases of diagnosed uterine leiomyomas admitted into the gynaecological ward of EBSUTH and managed were included in the study. Uterine leiomyomas in pregnancy or uterine leiomyomas discovered incidentally during other gynaecological/obstetric procedures were excluded. Also excluded from the study were patients who were diagnosed in the clinic with uterine fibroids but not admitted into the ward.

\section{Study Design}

This retrospective study reviewed data on all cases of uterine fibroid admitted into the gynaecological ward of the Ebonyi State University Teaching Hospital, Abakaliki (EBSUTH Ai) over the 5-year period (January 1, 2001 to December 31,2005$)$. The case notes were retrieved from the records department and data related to age, parity, uterine size at presentation, clinical history, investigation and treatment options were collated. Where surgery was the treatment chosen, the details relating to the type of surgery (elective or emergency), the techniques used to prevent excessive bleeding, estimated blood loss, blood transfusion and outcome of the treatment options were obtained.

Data was analyzed using SPSS Version 10.0. The mean, range and percentage were used to describe the quantitative data. Chi-square test used to test for significance and a p-value less than 0.05 was taken as significant.

\section{Result}

During the period of study, there were 1322 gynaecological admissions among which 180 were uterine leiomyomas. The case notes of 170 of these patients, which had complete information, were analyzed. Uterine leiomyomass constituted $13.6 \%$ of all the gynaecological admissions. The ages of the patients ranged from 19 to 55 years with a mean age of 34.3 17.0. Uterine leiomyomas were commonest in the $3^{\text {rd }}$ and $4^{\text {th }}$ decades of life $(74.1 \%)$ with the highest occurrence in the $4^{\text {th }}$ decade $(47.0 \%)$. The influence of age on the incidence of uterine leiomyoma was statistically significant $(p<0.05)$, (Table II).

Uterine leiomyoma was found more in nullipara, accounting for $48.8 \%$ of all cases, followed by multipara (para 1-4), $31.8 \%$, while $19.4 \%$ of cases were seen in grandmultipara. The association of low parity on the incidence of uterine leiomyoma was statistically significant $(p<0.05)$, (Table III). Though women in social classes 1 and 2, were found to have more uterine leiomyomas, $(21.2 \%$ and $21.8 \%$ respectively, the influence of social class on incidence of uterine leiomyoma was not statistically significant $(p>0.05)$, (Table IV).

Table I: The Socio-demographic characteristics of women with uterine leiomyoma.

( $N=170)$.

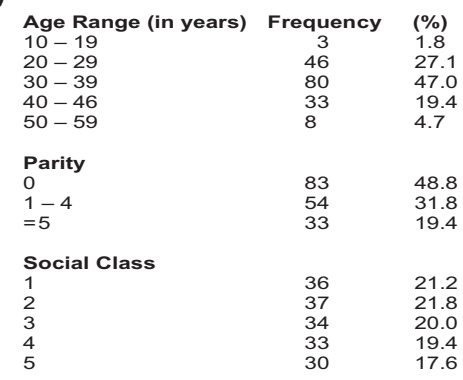

Table II: The Occurrence of uterine myomas by age of the woman compared with other gynaecological admissions.

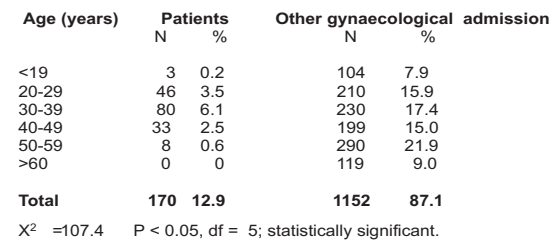

Table III: Parity among the 170 women with uterine myomas compared with other gynaecological admissions.

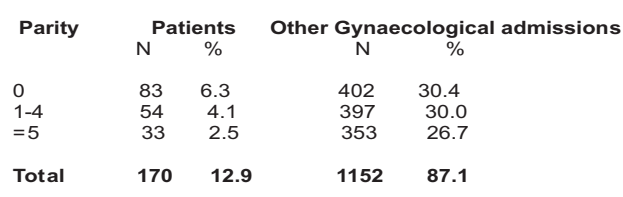

$\mathrm{X}^{2}=14.5, \mathrm{P}<0.05, \mathrm{df}=2$; statistically significant 
Table IV: Occurrence of uterine myomas by social class compared with other gynaecological admissions.

\begin{tabular}{|c|c|c|c|c|}
\hline Social class & \multicolumn{4}{|c|}{$\begin{array}{l}\text { Patients Other gynaecological admissions } \\
\mathrm{N} \%\end{array}$} \\
\hline 1 & 36 & 2.7 & 235 & 17.8 \\
\hline 2 & 37 & 2.8 & 228 & 17.3 \\
\hline 3 & 34 & 2.6 & 232 & 17.5 \\
\hline 4 & 33 & 2.5 & 237 & 17.9 \\
\hline 5 & 30 & 2.3 & 220 & 16.6 \\
\hline Total & 170 & 12.9 & 1152 & 87.1 \\
\hline
\end{tabular}

$X 2=0.05 . P>0.05, d f=4$; not statistically significant

Table V: Presenting Complaints of the Patients with uterine leiomyoma.

\begin{tabular}{lcc} 
Complaints & Number & \multicolumn{1}{l}{$\%$} \\
Infertility & 54 & 31.7 \\
$\quad$ Primary & 39 & 22.9 \\
$\quad$ Secondary & 15 & 8.8 \\
Lower abdominal swelling & 36 & 21.2 \\
Lower abdominal pain & 27 & 15.9 \\
Menorrhagia & 20 & 11.8 \\
Anaemia (PCV<30\%) & 20 & 11.8 \\
Irregular menses & 7 & 4.1 \\
Recurrent abortion & 6 & 3.5 \\
Total & $\mathbf{2 2 4}$ & $\mathbf{1 0 0}$
\end{tabular}

* Some patients presented with more than one complaint

Table Vl: Management options employed in the patients with uterine myomas

$\begin{array}{lcr}\text { Treatment modalities } & \text { Number } & \% \\ \text { 1. Total abdominal hysterectomy only (TAH) } & 6 & 3.5 \\ \text { 2. TAH + Bilateral salpingo cophorectomy } & 2 & 1.2 \\ \text { 3. Abdominal myomectomy only } & 153 & 90.0 \\ \text { 4. Polypectomy only } & 2 & 1.2 \\ \text { 5. Conservative management only } & 7 & 4.1\end{array}$

The common modes of presentation on admission as shown in table $\mathrm{V}$ were primary infertility $(22.9 \%)$, lower abdominal swelling (21.2\%), menstrual abnormalities $(15.9 \%)$, lower abdominal pain (15.9\%) and anaemia $(11.8 \%)$. One hundred and ten patients (84.7\%) had uterine leiomyomas whose sizes ranged from 12-20 weeks of gestation while fibroid masses whose size were above 20 weeks of gestation occurred in $22.9 \%$ of patients. Prior to surgery, 130 (76.5\%), $16(9.4 \%)$ and 5 $(2.9 \%)$ patients had pelvic ultrasonography, hysterosalpingography and intravenous urography respectively.

Table VI shows that $90 \%$ of the patients had abdominal myomectomy without additional procedures. Foley catheter was used as toumiquet during abdominal myomectomy in $76 \%$ of patients. Total abdominal hysterectomy with or without additional procedures was done for $4.7 \%$ of patients, while $1.2 \%$ of patients had polypectomy. All the surgeries were elective. Conservative management was applied in $4.1 \%$ of patients as none had any cause for surgery throughout the period of study.

Postoperative wound infection and dehiscence were the common complications noted in $3.5 \%$ and $2.4 \%$ respectively. Intra-operative haemorrhage complicated $1.8 \%$ of cases. There were no injuries to the adjacent structures/organs. No mortality was recorded. Fiftypatients $(29.5 \%)$ spent 7 days or less in the ward postoperatively, while $30(17.6 \%)$ patients spent more than 10 days before they were discharged. The commonest reason for hospital stay beyond 7 days was postoperative wound infection.

\section{Discussion}

The incidence of $13.6 \%$ of all the gyaecological admission is higher than the reported incidence of $6.58 \%$ at Ile-Ife, Western Nigeria ${ }^{2}$ and $10 \%$ in Ghana ${ }^{5}$. While this may represent population differences, it may as well reflect the different admission criteria into the gynaecological wards in the various centres. Meanwhile, this incidence may be lower than that of the local population as cases presenting at the gynaecological clinic and managed on out patient's basis were not included in the study. Moreover, many women with uterine fibroids are asymptomatic.

Most of the patients $(74.1 \%)$ in this study were in the prime of their reproductive age $\left(3^{\text {rd }}\right.$ and $4^{\text {th }}$ decades $)$, the incidence decreasing thereafter with age. No leiomyoma was found in women who were above 55 years. This compares with the report from lle-lfe ${ }^{2}$. This was not surprising because uterine fibroids are known to be estrogen-dependent ${ }^{2}$.

Nulliparity had significant association with uterine fibroids in this study as reported by Komolafe among the Yorubas of Southwestern Nigeria ${ }^{2}$. It is thought that myoma formation is a response of myometrial cells to hypoxic injuries during menstruation and prolonged exposure to menstrual cyclicity as is the case when pregnancy is delayed, may be responsible for the higher occurrence of uterine leiomyoma in the nullipara'. It may also explain why some grandmultipara who probably completed their families early in their 30 s because of early marriage which is common in this environment, may still be predisposed to uterine leiomyoma, $19.4 \%$ of grandmultipara in this study had uterine leiomyoma.

Uterine leiomyoma was found to be commoner in the higher social classes of 1 and 2, though this was not statistically significant. The higher social class is more likely to have delayed marriage and pregnancy due to career pursuit than the lower social class who indulges in early marriage, have higher parity and is not predisposed to obesity ${ }^{8}$. This finding differs from earlier view that uterine leiomyomas were commoner among 
the low socio-economic group ${ }^{1,2}$. The high parity among the women in the lower social class in our population could have been protective.

Uterine fibroids larger than 12 weeks gestation predominated in this survey $(87.6 \%)$ since it is larger fibroids that are likely to be symptomatic. Furthermore, though it has been reported that uterine fibroid tends to grow to a large size among the blacks ${ }^{1}$, it is not uncommon practice in this environment for women with gynaecological problems to first seek help from traditional medicine healers and prayer houses for a long time, resorting only to orthodox medical care when their initial efforts have failed. During this period, the fibroid grows to a large size.

The commonest mode of presentation of uterine fibroid in this study was infertility. This was at variance with the results from Ile-lfe and Enugu, Nigeria, where abnormal menstruation was the commonest mode of presentation ${ }^{2,10}$. In this retrospective study, it was difficult to ascertain whether leiomyoma was the only factor responsible for the infertility. However, it has been observed that $50 \%$ of patients undergoing myometomy for infertility will conceive within 1218 months of surgery and this may lend support that uterine fibroid may play some roles in the reproductive failure of some women ${ }^{2}$. Egwuatu, however, reported that only $9.6 \%$ of women who had myomectomy for infertility will conceive after surgery ${ }^{10}$ Some of the suggested mechanisms by which leiomyoma could cause infertility include: uterine distortion, associated chronic pelvic inflammatory diseases, hormonal imbalance, which favours both infertility and leiomyoma, and mechanical obstruction of the cervical canal and the fallopian tube ${ }^{2,11}$.

Ninety percent of the patients had abdominal myomectomy and $4.7 \%$ had Total Abdominal Hysterectomy (TAH) with or without additional procedures. The lle-lfe study among Yoruba recorded an abdominal hysterectomy rate of $46.6 \%{ }^{2}$. The premium placed on childbearing in marriage by the lgbos and the strong cultural aversion to surgical removal of the uterus may explain this wide margin of difference. Moreover, a sentimental attachment to menstruation by the Igbo women as an assurance of feminity and the superstitious belief that a hysterectomized woman will be infertile upon

\section{References}

1. Lower AM: Laparoscopic Myomectomy. In: Studd J (ed). Progress in Obstetrics and Gynaecology Volume 15. Edinburgh: elsevier Church-Hill Linvingstone 2003; 381 - 388. re incarnation may also contribute to this wide margin of difference ${ }^{12}$.

One hundred and twenty patients (70.5\%) were hospitalized for more than 8 days. This was not surprising because most of the patients had abdominal surgery which has been known to be associated with increased length of hospital stay compared to vaginal surgeries which are associated with shorter length of hospital stay ${ }^{7}$. Causes of prolonged hospital stay in this study were postoperative wound infections and dehiscence. The Foley catheter was used as tourniquet to reduce intra-operative blood loss. Kwawukume and Akinyemi, have both reported the effectiveness of this technique $e^{3,7}$.

Seven women (4.1\%) who were between the ages of 45 55 years had conservative management while the rest in this age bracket had either TAH or abdominal myomectomy. Conservative management has been found to be effective within this age range ( 4555 years) because of the absence of the effect of ovarian hormones (estrogen) on the fibroid mass ${ }^{8}$.

Wound infection was the commonest postoperative complication, accounting for $3.5 \%$ of cases. There were no deaths. These findings agree with the findings in Enugu, Nigeria, by Egwuatu ${ }^{10}$. The low incidence of operative complications and absence of mortality may be attributed to the status and competence of the surgeons, most of whom were consultants. This compares with the result from the lle-lfe?

A limitation of this study is a lack of follow-up of the patients on outcome measures such as pregnancy rate following myomectomy and the incidence of recurrence of the leiomyoma. Recurrence rates of $13.7 \%$ and $15 \%$ have been reported by Egwuatu and Akinyemi, respectively ${ }^{7,10}$.

In conclusion, uterine leiomyoma has remained a common indication for gynaecological admission in EBSUTH with primary infertility as the main presenting complaint. Myomectomy was the mode of treatment employed in most of the patients in order to preserve their menstrual and reproductive functions

2. Komolafe JO, Makinde NO, Ajadi AM and Dayo AA: Uterine Leiomyoma in Ile-Ife, Nigeria. Trop J Obstet Gynaecol 2004; 21:103 106. 
3. Kwawukume EY: Reduction of Blood Loss at Myomectomy by Application of Tourniquet to the Lower Portion of the Uterus. Trop J Obstet Gynaecol 2004; 21(2): 107109.

4. Fletcher HM and Frederick J: Abdominal Myomectomy Revisited. In: Studd J (ed). Progress in Obstetrics and Gynaecology volume 16. Edinburgh: Elsevier Church-Hill Livingstone 2005; 277286.

5. Seffah JD and Adanu RMK: Hysterectomy for uterine Fibroids in Nullipara at Korle Bu Teaching Hospital Ghana. Trop J Obstet Gynaecol 2005;22:125 128.

6. Ogedengbe OK: Uterine Fibroids. In: Okonofua FE and Odunsi KA (ed). Contemporary Obstetrics and Gynaecology for Developing Countries. Benin: Women health and Action research center (WHARC) 2003; 202213.

7. Akinyemi BO, Adewoye BR and Fakoya TA: Uterine Fibroids: A review. Nigerian J med (NJM) 2004; 13: 318329.
8. Lowe DG: Benigh Tumour of the Uterus. In: Edmonds DK (ed). Dewhurst's Textbook of Obstetrics and Gynaecology for Postgraduates, $6^{\text {th }}$ (ed). Oxford Blackwell Science Ltd. 1999; 552559.

9. Emuveyan EE, Ifenne DI and Ohaju-Obodo JA: A Randomized Controlled Study of Goserelin as Adjunctive Therapy Prior to Surgery in the Management of uterine fobroids. Top J Obstet Gynaecol 2005; 22:120 124.

10. Egwuatu V.E: Fertility and fetal Salvage Among Women With Uterine Leiomyomas in a Nigerian Teaching Hospital. Int $\mathrm{J}$ Fertil,1989; 34:341-346.

11. Doyle K: Leiomyomatous uterus. In: Frederickson HL and Wilkins-Haug L (ed). Ob/Gynae secret, $2^{\text {nd }}$ ed. Philadelphia: Hanley and Belfus Inc. 1997; 30-32.

12. Umeora OUJ and Egwuatu VE. Menstruation in Igbo Women of South East Nigeria, Attitudes, Beliefs and Practice. Afr $\mathrm{J}$ of Reprod Health. In Press. 